\title{
Aspectos fisicoquímicos e citológicos do líquido sinovial da articulação temporomandibular de equinos em diferentes idades ${ }^{1}$
}

\author{
Roberto dos Santos Zambrano ${ }^{2}$, Fernanda Assis Fonseca ${ }^{2}$, Júlia de Miranda Moraes ${ }^{2}$, Glaúcia \\ Mansur Balsamão Dias², Geraldo Eleno Silveira Alves², Eduardo Maurício Mendes Lima², \\ André Rodrigues da Cunha Baretto Vianna ${ }^{2}$ e Roberta Ferro de Godoy ${ }^{2^{*}}$
}

\begin{abstract}
Zambrano R.S., Fonseca F.A., Dias G.M.B., Alves G.E.S., Lima E.M.M., Vianna A.R.C.B. \& Godoy R.F. 2011. [Cytological and physicochemical aspects of the temporomandibular joint synovial fluid of horses in different ages.] Aspectos fisicoquímicos e citológicos do líquido sinovial da articulação temporomandibular de equinos em diferentes idades. Pesquisa Veterinária Brasileira 31(10):926-932. Faculdade de Agronomia e Medicina Veterinária, Universidade de Brasília, ICC Sul, Campus Universitário Darcy Ribeiro, Cx. Postal 4508, Brasília, DF 70910-970, Brazil. E-mail: robertagodoy@unb.br

The synovial fluid analysis is very important to identify cytology and chemical modifications of suppurative and nonsuppurative inflammatory diseases, bleeding, neoplasm or infectious diseases. The aim of this study was to analyze the physicochemical and cytological aspects of temporomandibular joint synovial fluid in 24 healthy horses, 12 males and 12 females, who were divided into four groups: control group (Gc) with age varied between five to 13 years, group 1 (G1), with ages varied between five and seven years, group 2 (G2) age varied between eight and ten years and group 3 (G3) with age varied between 11 and 13. The synovial fluid was evaluated for volume, $\mathrm{pH}$, density, glucose, total protein, red blood cells, nucleated cells, neutrophils, lymphocytes and macrophages. The animals in this study were treated for minor dental abnormalities and it was not possible to detect changes in physicochemical and cytologic synovial fluid between the different groups.
\end{abstract}

INDEX TERMS: Joint, morphophysiology, equine dentistry.

RESUMO.- A análise do líquido sinovial é de grande importância para identificar alterações citológicas e químicas de afecções inflamatórias supurativas e não supurativas, hemorragias, neoplasia ou doenças infecciosas. 0 objetivo deste estudo foi analisar os aspectos fisicoquímicos e citológicos do líquido sinovial da articulação temporomandibular em 24 equinos hígidos, sendo 12 machos e 12 fêmeas, que foram divididos em quatro grupos, sendo um grupo controle (Gc) com a idade variando de cinco a 13 anos, grupo 1 (G1) com a idade variando entre cinco e sete anos, gru-

\footnotetext{
${ }^{1}$ Recebido em 8 de agosto de 2011.

Aceito para publicação em 14 der setembro de 2011.

${ }^{2}$ Faculdade de Agronomia e Medicina Veterinária, Universidade de Brasília (UnB), ICC Sul, Campus Universitário Darcy Ribeiro, Caixa Postal 4508, Brasília, DF 70910-970, Brasil. *Autor para correspondência: robertagodoy@unb.br
}

po 2 (G2) com idade variando entre oito e dez anos e grupo 3 (G3) com idade que varia entre 11 e 13 anos. 0 líquido sinovial foi avaliado quanto ao seu volume, $\mathrm{pH}$, densidade, glicose, proteínas totais, hemácias, células nucleadas, neutrófilos, linfócitos e macrófagos. Os animais do presente estudo foram tratados para alterações dentárias leves e não foi possível detectar alterações fisicoquímicas e citológicas no líquido sinovial entre os diferentes grupos.

TERMOS DE INDEXAÇÃO: Articulação, morfofisiologia, odontologia equina.

\section{INTRODUÇÃO}

A biomecânica mastigatória dos equinos pode ser prejudicada pela alteração do ângulo de oclusão fisiológico dos dentes pré-molares e molares, que modifica a correspondência do ângulo da arcada dentária e dos côndilos man- 
dibulares, interferindo no equilíbrio entre as arcadas e as articulações temporomandibulares. A alteração da correspondência entre os ângulos dentários e articulares pode, a médio ou longo prazo, colaborar para a ocorrência de artropatias nas articulações temporomandibulares.

O líquido sinovial é um dialisado do plasma, que também contém substâncias secretadas pelos próprios tecidos articulares, incluindo uma quantidade relativamente alta de ácido hialurônico. Suas principais funções são lubrificar e nutrir a cartilagem articular, a qual não tem vasos sanguíneos, linfáticos ou nervos (Parry 1999).

A análise do líquido sinovial é realizada para identificar alterações citológicas e químicas de afecções inflamatórias supurativas e não supurativas, hemorragias, neoplasia ou doenças infecciosas (Kiehl 1997). 0 líquido sinovial reflete alterações no tecido sinovial (Van Pelt 1962) e no metabolismo intra-articular ocasionadas pela doença (Van Pelt 1962, 1974). Informações obtidas pela análise do fluido podem indicar a natureza e a extensão das lesões intra-articulares e contribuir com outras técnicas auxiliares na determinação do diagnóstico, na definição do tratamento (Tew \& Hotchkiss 1981) e no seu acompanhamento (Moyer 1983, Barnabé et al. 2005), possibilitando estabelecer prognóstico fidedigno (Tew \& Hotchkiss 1981).

Atualmente, na clínica de equinos a odontologia é restrita à identificação e tratamento das patologias dentárias, sem preocupação com sua possível relação com alterações da articulação temporomandibular. Além disso, é sabido que alterações dentárias nos equinos refletem em alterações comportamentais, porém a dor na articulação temporomandibular pode ser a principal causadora destas alterações (Moll \& May 2002).

Nos equinos, as alterações da ATM podem estar associadas diretamente aos problemas dentários. Sabe-se que anormalidades dentárias levam à inflamação da articulação e consequente dor, diminuindo o desempenho do animal podendo causar problemas comportamentais. Porém existem poucos estudos científicos a respeito da articulação temporomandibular em equinos, sendo que a maioria das informações vem de comparações com estudos desta estrutura em humanos (Moll \& May 2002).

Neste contexto o presente estudo teve como objetivo avaliar as características fisicoquímicas e citológicas do líquido sinovial da articulação temporomandibular em equinos de diferentes idades, avaliando ainda a influência do tratamento dentário sobre estas características.

\section{MATERIAL E MÉTODOS}

A coleta de dados foi realizada no 1 o Regimento de Cavalarias de Guardas (1ํRCGd - "Dragões da Independência”, Brasília-DF), em eqiinos de propriedade do Exército Brasileiro. Para tanto foram utilizados 24 equinos, da raça Brasileiro de Hipismo, sendo 12 fêmeas e 12 machos, sendo todos portadores de alterações dentárias. Estes foram divididos em quatro grupos experimentais de seis animais cada sendo que Gc = grupo controle, idade variando de cinco a 13 anos, G1 = idade variando de cinco a sete anos, G2 = idade variando de sete anos e um mês até dez anos e G3 = idade variando de dez anos e um mês até 13 anos. Para a verificação da idade foi utilizado um prontuário individual de propriedade do
Exército Brasileiro e confirmação pelo exame das arcadas dentárias. Este trabalho foi submetido e aprovado pelo Comitê de Ética no Uso Animal da Universidade de Brasília (CEUA-UnB), sob processo UnBDOC $n^{\circ} 29237 / 2009$ por estar de acordo com os princípios éticos do Colégio Brasileiro de Experimentação Animal (COBEA).

Para determinação daqueles com alterações dentárias os animais foram submetidos a exame odontológico com emprego de abridor de boca e fotóforo, após terem sido sedados com xilazina $10 \%$ (Sedazine ${ }^{\circledR}$, Fort Dodge, Campinas-SP, BR) na dose de $0,5 \mathrm{mg} / \mathrm{kg} / \mathrm{IV}$. Como protocolo para cada animal, foi realizada anamnese quanto às possíveis alterações relacionadas a problemas dentários, como desconforto durante a mastigação, rebeldia à montaria e à embocadura, queda de alimento da boca, emagrecimento progressivo e episódios de cólicas. Daí o animal com alterações dentárias foi alocado no correspondente grupo de acordo com sua idade. As alterações encontradas foram resenhadas em ficha odontológica específica, contendo as imagens fotográficas digitais de antes e após o tratamento.

Inicialmente os animais de cada um dos grupos foram pesados utilizando-se balança eletrônica Toledo MGR Junior 3000, imediatamente antes da coletas do líquido sinovial, ou seja, antes do tratamento dentário (T0) e 60 dias (T60) após a correção das alterações. Em seguida a correção dentária foi realizada com auxílio de um abridor de bocas (Ortovet, Paraíso-SP, BR), motor elétrico de alta rotação (18.000rpm) (Bordente, São Paulo-SP, BR), caneta de 20 polegadas com broca diamantada cilíndrica, e grosagem manual utilizando-se "kit" de grosas de alumínio com "blades" de carbeto (Ortovet, Paraíso-SP, BR). Ainda como complemento do material odontológico foi utilizado: cabeçada odontológica, fotóforo (Rayovac, São Paulo-SP, BR), motor elétrico de alta rotação (33.000 rpm) (Dremel, Racine, Wisconsin, USA) e levantadores apicais (Ortovet, Paraíso-SP, Brasil). Desta forma empregou a mesma técnica descrita por Easley (2005), em que foi retirada as pontas dentárias, ganchos e degraus com o motor de alta rotação, em seguida, promoveu-se as correções mais delicadas com as grosas manuais, permitindo assim, a cicatrização das feridas orais provocadas por essas alterações. Foi corrigido primeiramente a arcada superior e em seguida a arcada inferior. A retirada dos $1^{0}$ pré-molares superiores e a correção dos incisivos fez parte da última etapa do tratamento odontológico.

Visando a coleta do líquido sinovial os animais foram contidos em brete de contenção próprio para equinos, em seguida sedados com xilazina $10 \%(0,5 \mathrm{mg} / \mathrm{kg})$ por via intravenosa. Para tal, realizou-se tricotomia na região da articulação temporomandibular e antissepsia com iodopovidona degermante. A punção foi realizada na porção caudal do compartimento dorsal da articulação. 0 côndilo da mandíbula foi identificado na porção média, entre a comissura lateral do olho e a base da orelha. O processo zigomático do osso temporal foi palpado a $1 \mathrm{ou} 2 \mathrm{~cm}$ dorsalmente ao côndilo da mandíbula e uma linha imaginária foi traçada entre estas duas estruturas. Em seguida o local para a punção foi a depressão na área de menor resistência à palpação entre estas duas estruturas, ou seja, de 0,5 a $1 \mathrm{~cm}$ caudalmente à linha imaginária. A agulha foi inclinada levemente, em sentido rostroventralmente, em uma angulação de aproximadamente $15^{\circ}$ e aprofundada aproximadamente 1,25 a $3 \mathrm{~cm}$. As coletas de líquido sinovial foram realizadas nas articulações, de ambos os antímeros, de cada animal de acordo com Schumacher (2006) e Rosenstein et al. (2001).

Para a coleta de líquido sinovial, utilizou-se seringas de $3 \mathrm{~mL}$ e agulhas descartáveis $25 \times 07 \mathrm{~mm}$. As amostras de foram imediatamente divididas em dois tubos, sendo um sem anticoagulante para dosagem de proteína total pelo método de biureto e outro tubo com anticoagulante EDTA (ácido etilediaminotetracético, sal 
dissódico), a 10\%, para as demais variáveis. Após a coleta do líquido sinovial, foi realizada a coleta de sangue venoso por punção da veia jugular externa esquerda, com dispositivo para coleta a vácuo em tubo descartável de $13 \times 75 \mathrm{~mm}$ (Vacuette $\AA$, Greiner Bio-One, São Paulo-SP, BR) e agulhas descartáveis $25 \times 0,8 \mathrm{~mm}$, sendo divididos em três alíquotas: um tubo com anticoagulante EDTA para realização de hemograma completo, dosagem de proteína total e fibrinogênio; um tubo com fluoreto de sódio para dosagem de glicose plasmática e; um tubo sem anticoagulante para dosagem de fosfatase alcalina e aspartato aminotransferase. Logo após as coletas todas as amostras foram refrigeradas e encaminhadas para as análises laboratoriais.

Os procedimentos laboratoriais foram realizados no Laboratório Santé (Brasília-DF, BR). Todos os equipamentos utilizados estavam calibrados periodicamente (controle interno) com uso de padrões de calibração e certificados (ensaio de proficiência) por empresa acreditadora (Controllab, Rio de Janeiro-RJ, BR). 0 sangue foi submetido a estudos laboratoriais, incluindo contagens globais de hemácias, leucócitos e plaquetas, assim como a determinação do hematócrito e da concentração de hemoglobina, todos com o auxílio do contador automático de células (Abacus Junior Vet - Diatron, São Paulo-SP, BR). As contagens diferenciais de leucócitos foram realizadas em esfregaços sanguíneos corados com Panótico, enumerando-se 100 células e estabelecendo-se as fórmulas leucocitárias relativa e absoluta. Para análise bioquímica das amostras sanguíneas foi utilizado analisador semi-automático (Bio 2000 - Bioplus, São Paulo-SP, BR) com auxílio de um conjunto de reagentes (Labtest- Sistema de Diagnósticos Ltda.- Belo Horizonte- MG, BR).

De outra forma foram avaliadas as características físico-químicas (aspecto, volume, coloração, turbidez, viscosidade e proteína total (PT) e celulares do líquido sinovial, sendo o aspecto, o volume e a viscosidade, verificados no momento da coleta de cada amostra como estabelecido por Piermattei \& Flo (1997) e Boon (1997). A determinação da viscosidade foi realizada no momento da transferência do líquido sinovial da seringa de coleta para os tubos de ensaio. Dessa forma, foi estimado o comprimento, em centímetros, do filamento formado pela gota após se desprender da agulha. Considerou-se a viscosidade diminuída quando o comprimento do filamento foi inferior a $5 \mathrm{~cm}$, sendo atribuídos escores numéricos de 1 para viscosidade diminuída e 2 para viscosidade normal.

Como proposto por Fonseca et al. (2009) o pH e a concentração de glicose do líquido sinovial foram mensurados por meio de fita Combur-test (Roche Diagnostics, Basel- $\mathrm{CH}$ ). A densidade e proteína total do líquido sinovial foram mensuradas com refratômetro (ATAGO Yushima, JP). Visando ainda o estabelecimento de dados específicos ao líquido sinovial as contagens globais de hemácias e de células nucleadas foram realizadas com hematocitômetro de Neubauer e com contador automático de células (Abacus Junior Vet - Diatron, São Paulo-SP, BR). As contagens diferenciais de células nucleadas, deste mesmo líquido, foram realizadas em lâminas de vidro coradas pela técnica de Panótico como descrito por Mahaffey (2001). Para tanto as amostras foram centrifugadas durante três minutos a 3500rpm para a obtenção do sedimento e posterior confecção das lâminas para a análise citológica. Foram contadas 100 células nucleadas de cada lâmina, sendo classificadas como linfócitos, grandes células mononucleares, neutrófilos segmentados e eosinófilos. As grandes células mononucleares constituíram-se de monócitos, macrófagos e eventuais células da membrana sinovial. Preparou-se também outra lâmina com a coloração de Gram para a pesquisa de bactérias.

Inicialmente realizou-se a estatística descritiva dos dados, obtendo-se as médias, desvio padrão e coeficiente de variação para todos os parâmetros avaliados, bem como, as frequências para as características subjetivas. Os dados foram submetidos a aplicação do teste de normalidade Kolmogorov-Smirnov. A partir de então as variáveis paramétricas foram comparadas entre os tempos T0 e T60 de cada grupo, empregando-se o teste "T" de Student ao nível de significância $\mathrm{p} \leq 0,05$.

\section{RESULTADOS}

De acordo com os dados analisados, as características do líquido sinovial das articulações temporomandibulares dos equinos, antes e depois do sofreram pouco influência do tratamento dentário. Acredita-se que as alterações dentárias encontradas nesse experimento não foram suficientes para influenciar e modificar o líquido sinovial em relação as suas características físico-quimicas e citológicas das articulações estudadas. Da mesma forma o tempo entre as análises e coletas foi insuficiente para promoverem diferenciações.

Foi possível observar que de uma forma geral as alterações dentárias encontradas nos animais dos diferentes grupos eram pouco acentuadas. Todos os animais examinados, nos três grupos apresentavam pontas excessivas de esmalte dentário (PEED). Além disso, no G1, um animal $(16,67 \%)$ possuía ganchos em dois molares. No G2, além das PEED, foi observada a ocorrência de degrau em um animal $(16,67 \%)$ e ganchos em dois molares em outro animal também em 16,67\%. Mordedura cruzada foi observada em $16,67 \%$, ganchos em dois molares em $16,67 \%$ e degraus em dois molares em $16,67 \%$ foram alterações verificadas no G3, além das PEED.

Os dados relativos às características da análise fisicoquímica e citológica do líquido sinovial antes e depois do tratamento nos grupos controle, 1, 2 e 3 foram apresentados nos Quadros 1, 2, 3 e 4, respectivamente. A partir da obtenção destes parâmetros aplicou-se ainda o teste "T" de Student visando retratar por meios quantitativos a presença de diferença estatística entre o momento T0 do grupo controle e as demais variáveis dos grupos 1, 2 e 3, entre os momentos T0 e T60. Com isso não foram observadas diferenças estatísticas entre nenhum dos dados analisados entre os grupos.

Ainda como parte dos resultados obtidos no presente estudo pode-se ver que os animais tiveram um efetivo um ganho de peso (Quadros 1 e 3). Isto pode ter ocorrido pelo fato mesmo que sem alterações dentárias acentuadas, as resoluções das mesmas geraram uma melhor mastigação e uma digestão mais efetiva. Em nenhum momento os animais do Exército Brasileiro foram retirados de sua rotina, como embarque e desembarque de viaturas, desfiles, representações, escoltas e adestramento do efetivo de militares do aquartelamento. Foi ainda importante relatar os animais apresentaram uma melhora no desempenho, isto em relação à condução, obtendo maior relaxamento, característica esta relatada pelo cavaleiro.

Não houve diferença significativa $(p \leq 0,05)$ antes e depois do tratamento dentário em relação aos parâmetros sanguíneos e bioquímicos e todos os dados encontraram-se dentro dos valores de referência para a espécie e idade. 
Quadro 1. Valores absolutos dos pesos de equinos dos diferentes grupos submetidos a tratamento dentário

\begin{tabular}{|c|c|c|c|c|c|c|c|c|}
\hline & \multicolumn{2}{|c|}{ GC } & \multicolumn{2}{|c|}{ G1 } & \multicolumn{2}{|c|}{ G2 } & \multicolumn{2}{|c|}{ G3 } \\
\hline & T0 & $\mathrm{T} 60$ & T0 & T60 & T0 & $\mathrm{T} 60$ & T0 & T60 \\
\hline Média & $516,33^{*}$ & 522,83 & $448,17^{*}$ & 440,83 & 494,83 & 501,67 & 512,83 & 528,50 \\
\hline Desvio Padrão & 33,43 & 36,42 & 28,62 & 22,82 & 22,46 & 26,33 & 32,41 & 26,12 \\
\hline
\end{tabular}

$\overline{\mathrm{GC}}=$ grupo controle, $\mathrm{G} 1=$ grupo $1, \mathrm{G} 2$ = grupo $2, \mathrm{G} 3$ = grupo 3 , $\mathrm{T} 0$ = primeira coleta e $\mathrm{T} 60$ = segunda coleta. Os valores entre as colunas sobrescritos por * asterisco expressam diferença estatística entre as variáveis de acordo com a aplicação do teste T Student com nível de significância de 5\%.

Quadro 2. Valores das médias e desvios padrão das variáveis analisadas do líquido sinovial de equinos submetidos a tratamento dentário

\begin{tabular}{|c|c|c|c|c|c|c|c|}
\hline & \multirow{2}{*}{$\frac{\mathrm{GC}}{\mathrm{T} 0}$} & \multicolumn{2}{|c|}{ G1 } & \multicolumn{2}{|c|}{ G2 } & \multicolumn{2}{|c|}{ G3 } \\
\hline & & T0 & T60 & T0 & T60 & T0 & $\mathrm{T} 60$ \\
\hline Volume (mL) & $0,28 \pm 0,21$ & $0,83 \pm 0,71$ & $0,85 \pm 0,14$ & $0,71 \pm 0,17$ & $0,68 \pm 0,15$ & $0,51 \pm 0,15$ & $0,4 \pm 0,13$ \\
\hline $\mathrm{Ph}$ & $8,22 \pm 0,44$ & $8,08 \pm 0,29$ & $8,0 \pm 0,28$ & $8,0 \pm 0,24$ & $8,0 \pm 0,23$ & $8,0 \pm 0,24$ & $8,17 \pm 0,41$ \\
\hline Densidade & $1021 \pm 2,37$ & $1018,5 \pm 2,54$ & $1019,3 \pm 2,77$ & $1020,16 \pm 2,76$ & $1020,75 \pm 2,49$ & $1026,2 \pm 4,76$ & $1021,66 \pm 0,98$ \\
\hline Glicoese (mg/dL) & $<50$ & $<50$ & $<50$ & $<50$ & $<50$ & $<50$ & $<50$ \\
\hline Proteínas totais $(\mathrm{g} / \mathrm{dL})$ & $4,41 \pm 0,55$ & $3,75 \pm 0,58$ & $4,41 \pm 0,55$ & $4,15 \pm 0,82$ & $4,47 \pm 0,54$ & $5,46 \pm 1,11$ & $4,26 \pm 0,54$ \\
\hline $\begin{array}{l}\text { Neutrófilos segmentados } \\
\text { (células } / \mu \mathrm{L} \text { ) }\end{array}$ & $110,55 \pm 128$ & $67,73 \pm 69,08^{a}$ & $80,38 \pm 74,41^{b}$ & $45,98 \pm 40,24$ & $52,76 \pm 48,30$ & $172,4 \pm 231,26$ & $182,2 \pm 237,31$ \\
\hline Linfócitos (células/ $\mu \mathrm{L}$ ) & $565 \pm 108$ & $582,62 \pm 429,84$ & $472,14 \pm 328,71$ & $633,4 \pm 385,32$ & $552,75 \pm 318,34$ & $382,29 \pm 264,25$ & $700,8 \pm 570,21$ \\
\hline Macrófagos (células/ $\mu \mathrm{L}$ ) & $35,44 \pm 4,25$ & $72,73 \pm 67,57$ & $86,88 \pm 50,53$ & $78,42 \pm 50,84$ & $81,54 \pm 55,52$ & $33 \pm 36,50$ & $74,4 \pm 98,43$ \\
\hline
\end{tabular}

$\overline{\mathrm{GC}}=$ grupo controle, $\mathrm{G} 1=$ grupo $1, \mathrm{G} 2=$ grupo $2, \mathrm{G} 3=$ grupo $3, \mathrm{~T} 0=$ primeira coleta e $\mathrm{T} 60$ = segunda coleta. Os valores entre as linhas sobrescritos por diferentes letras expressam diferença estatística entre as variáveis de acordo com a aplicação do teste "T" Student com nível de significância de $5 \%$.

Quadro 3. Valores das médias e desvios padrão da avaliação física e hematológica de equinos submetidos a tratamento dentário

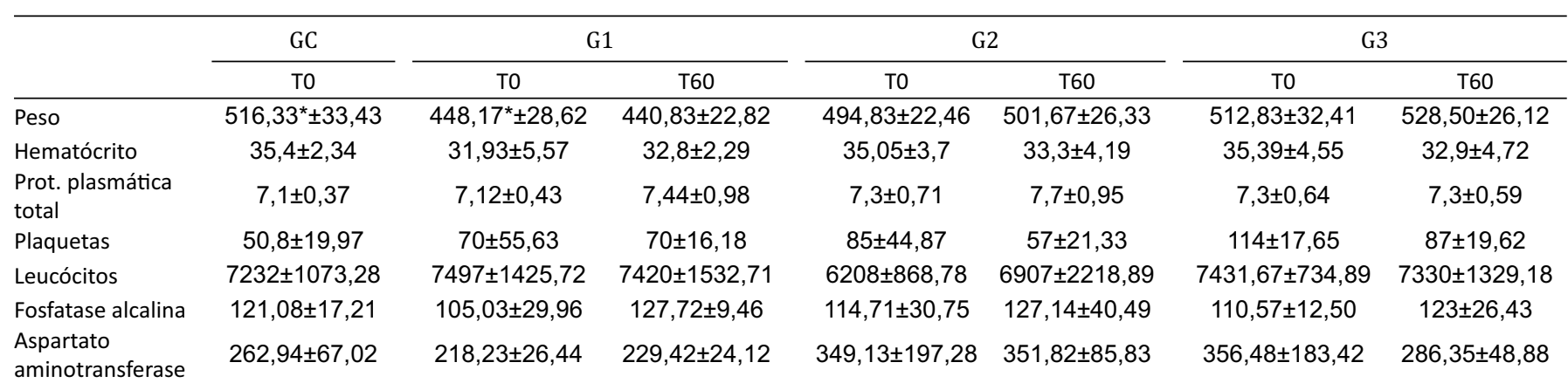

$\mathrm{GC}=$ grupo controle, $\mathrm{G} 1$ = grupo $1, \mathrm{G} 2$ = grupo $2, \mathrm{G} 3$ = grupo 3, $\mathrm{T} 0$ = primeira coleta e $\mathrm{T} 60$ = segunda coleta. Os valores entre as colunas sobrescritos por * asterisco expressam diferença estatística entre as variáveis de acordo com a aplicação do teste T Student com nível de significância de $5 \%$.

Com relação às variáveis do líquido sinovial, não houve diferença significativa em nenhum parâmetro analisado (viscosidade, hemácias, células nucleadas, linfócitos, macrófagos e neutrófilos segmentados). Já em relação a coloração das amostras de líquido sinovial foi possível observar que no G1 esse líquido apresentou-se amarelo claro em $60 \%$ dos animais, para T0 e T60. Já em relação aos animais do G2 esse achado representou $91,66 \%$ em T0 e $75 \%$ para T60. Para o G3 a coloração amarela claro foi encontrada em $58,33 \%$ dos animais em T0 e $75 \%$ em T60. 0 restante das amostras, inclusive os animais do grupo controle, o líquido sinovial apresentou coloração amarela avermelhada a vermelha e aspecto turvo.
A densidade e à proteína total apresentou um aumento gradativo entre os grupos sendo respectivamente de 1018,5 e $3,75 \mathrm{mg} / \mathrm{dl}$ no G1, 1020,16 e $4,15 \mathrm{mg} / \mathrm{dl}$ no G2 e 1026,2 e $5,46 \mathrm{mg} / \mathrm{dl}$ no G3, no T0. Já em relação a T60, a densidade e a proteína total foram respectivamente de 1019,3 e 4,41mg/ dl no G1, 1020,75 e 4,47mg/dl no G2 e 1021,66 e 4,26mg/ dl G3. Sobretudo sem diferença estatística quando avaliado essa densidade para o grupo controle. Nos três grupos foi possível observar uma relação inversamente proporcional da densidade e proteína total comparando com o volume de líquido dessa articulação (Quadro 2).

$0 \mathrm{pH}=8,0$ foi observado em $80 \%$ das amostras dos animais observados em T0 e T60. Já para os animais de G2 o 
$\mathrm{pH}=8,0$ foi verificado em $100 \%$ das amostras nos dois momentos e para os animais do $\mathrm{G} 3$ o $\mathrm{pH}=8,0$ esteve presente em $91,66 \%$ no T0 e em $100 \%$ no T60, conforme o Quadro 1.

\section{DISCUSSÃO}

Em relação à influência do tratamento pode-se ver que o tempo de intervalo entre as análise do líquido sinovial foi determinante nos resultados, pois pode ter sido insuficiente para gerar alterações significantes nas características desse líquido. Neste contexto foi possível encontrar o estudo de Carmalt et al. (2004), que em estudo similar, determinou um tempo de intervalo de 20 semanas, quando pode encontrar alterações no líquido sinovial, sobretudo não encontrou ganhos significativos em relação ao peso e digestibilidade.

No tocante as alterações dentárias encontradas nos animais empregados neste estudo, observa-se que estes achados foram de encontro com os achados de Ralston et al. (2001), que afirmou que pontas dentárias e ganchos não foram capazes de interferirem significativamente na digestibilidade dos alimentos em equinos. Ainda neste contexto, Carmalt et al. (2004) afirmou que essas mudanças sofreram interferência do tempo em que elas se fazem presentes, principalmente em relação ao ganho de peso, escore corporal, digestibilidade ou tamanho da partícula fecal. Sendo assim, embasados nestes relatos podemos extrapolar que as alterações dentárias encontradas, mesmo que não sendo possível determinar o tempo em que elas se faziam presentes, mesmo após o tratamento e a eliminação das mesmas não foram capazes de promoverem acentuadas modificações nos equinos estudados. De outra forma, Pimentel (2008) descreveu, que de acordo com relato dos proprietários e equitadores, em $65,2 \%$ de animais que foram submetidos a tratamento odontológico ganharam peso e massa muscular, mesmo que, outros fatores como clima, qualidade de forragem, tenham influenciado estes parâmetros no período de 90 a120 dias após a intervenção odontológica. Para Pagliosa et al. (2006), em equinos com PEED, que foram submetidos a tratamento odontológico, após duas semanas, não houve alteração do estado corporal dos animais. Sendo ainda que estes ganhos demandam de um tempo maior após o tratamento das afecções dentárias. Mesmo que seja possível sugerir que o ganho de peso possa ser resultado da eliminação de processos dolorosos em músculos mastigatórios ou na eliminação do trauma mecânico, que atuavam efetivamente sobre a mucosa oral e língua, causado pelas alterações dentárias.

A não alteração dos parâmetros hematológicos e bioquímicos, antes e após o tratamento dentário para os equinos deste estudo, sugeriu que apesar de apresentarem alterações dentárias, os mesmos apresentavam uma boa sanidade. Sendo assim, foi possível sugerir que estas alterações não foram capazes de influenciar efetivamente, e de maneira acentuada, na alteração destes parâmetros.

Em todos os grupos, os resultados da contagem de células nucleadas no líquido sinovial da articulação temporomandibular, tanto antes quanto depois do tratamento dentário, ultrapassaram os valores considerados limite conforme o estabelecido por a Duncan \& Prasse (1986), bem como o citado por Fonseca et al. (2009). Neste contexto Spiers et al. (1994), mencionaram que células nucleadas responderam pela produção de substâncias importantes ao equilíbrio fisiológico do líquido sinovial e, consequentemente, da articulação, demonstrando assim ser de extrema importância que sejam encontradas em quantidades adequadas neste líquido. Sobretudo, este aumento de células nucleadas foi um fator isolado, e da mesma forma não apresentou diferença estatística entre os grupos tratados e o grupo controle. Portanto pode-se atribuir esta característica à individualidade dos animais, ou ainda, à presença de sangue proveniente de vasos sanguíneos dispostos na membrana sinovial da cápsula articular da articulação.

Em relação às amostras de líquido sinovial analisadas nos grupos tratados foi possível observar que estas apresentaram viscosidade adequada nos dois momentos das coletas. A viscosidade segundo Sawyer (1963) e Fernandez et al. (1983) poderia ainda ser avaliada também colocando uma gota entre os dedos indicador e polegar e ao afastá-los, estimando-se assim subjetivamente a qualidade do cordão que se formou, sendo então normal, reduzida ou muito reduzida. Foi possível observar que a viscosidade mostrou-se como sendo uma função estabelecida diretamente em relação à concentração e qualidade do ácido hialurônico contido e constituinte do líquido sinovial das articulações. Apresentando-se assim diminuída em várias artrites inflamatórias devido à despolimerização deste ácido, por proteases inflamatórias e bacterianas (Mac Willians \& Friedrichs 2003). De outra forma efusões que diluem o líquido sinovial poderiam diminuir essa viscosidade, sendo que líquido articular de baixa viscosidade frequentemente foi observado em articulações inflamadas, e ocasionalmente em articulações traumatizadas ou degeneradas (Mac Willians 2003). A viscosidade normal em todos os momentos de coleta e em todos os grupos indicou normalidade do líquido sinovial, podendo-se assim inferir que as alterações dentárias encontradas nestes equinos talvez não tenham sido graves o suficiente para causar alterações deste parâmetro.

No tocante a coloração das amostras de líquido sinovial, pode-se observar que a porcentagem de amostras que apresentou coloração amarela claro, isto é coloração normal, conforme o proposto por Mahaffey (2001), para os animais do G1 foi de 60\% no T0 e T60. Já em G2, $91,66 \%$ das amostras apresentaram-se com coloração amarela claro em T0 e 75\% em T60. Em G3 a coloração amarela claro das amostras foi de 58,33\% T0 e $75 \%$ no T60. De outra forma o restante das amostras nos três grupos apresentou coloração amarela avermelhada tendendo a vermelha de aspecto turvo, sendo que, segundo Barnabé et al. (2005), essa porcentagem de coloração alterada encontrada foi determinada pelo processo de punção da articulação. Sendo consequência da ruptura de capilares subsinoviais, podendo ser confirmada pela inexistência de amostras com coloração alterada no início da punção e ausência de xantocromia após sua centrifugação, sendo ainda que este achado foi confirmado por Mac Willians \& Friedrichs (2003). 
Em relação ao volume de líquido sinovial coletado na articulação temporomandibular dos equinos deste estudo, pode-se verificar uma diminuição das quantidades coletadas deste líquido, entre os tempos de coleta para os animais de G2 e G3. Sugere-se que esta diminuição seja devido ao tempo entre as coletas, que pode ter sido insuficiente para haver reconstituição total do volume do líquido sinovial, sobretudo deve ser ressaltado que não foi verificada diferença estatística entre os grupos. Também foi observado um menor volume de líquido sinovial obtido para os animais do G3 em relação aos G2 e G1 e no G2 em relação ao G1. Foi possível observar que os achados foram considerados normais em relação com a idade mais avançada dos animais, principalmente no tocante as cavidades articulares apresentando uma menor quantidade de líquido sinovial. Este achado foi observado visualmente no momento das coletas, sobretudo deve ser ressaltado que não foram encontradas diferença estatística entre os grupos.

Com relação à densidade e à proteína total, observou-se aumento gradativo entre os grupos. Demonstrando uma relação inversa entre a densidade e proteína total em relação ao volume do líquido sinovial. Revelando assim que à medida que o animal envelhece, o volume deste líquido sofre uma diminuição, tornando assim mais denso e com uma concentração maior de proteína, assim como observado por Viitanen et al. (2001). Portanto mostrou-se importante que fatores como a idade pode influenciar naturalmente nas modificações da estrutura das articulações, determinando-se desta forma que alterações na articulação poderiam promover modificações nos diferentes parâmetros da articulação sinovial, dentre estes a proteína.

$\mathrm{O} \mathrm{pH}$ do líquido sinovial dos animais deste estudo esteve um pouco acima dos valores de referência propostos por Saywer (1963), mas dentro do limite encontrado por Fonseca et al. (2009). Portanto foi possível sugerir que esta pequena diferença, mesmo que sutil poderia indicar características individuais dos animais utilizados, não sendo assim refletir necessariamente de uma maneira geral as alterações do líquido sinovial. Pois não foi possível verificar a ocorrência de diferença significativa entre o pH entre os grupos de animais empregados.

A concentração média de glicose no líquido sinovial se mostrou abaixo do limite inferior da concentração plasmática de glicose considerada normal $(75-115 \mathrm{mg} / \mathrm{dL})$ para a espécie, conforme descrito por Curtiss (1964), Van Pelt (1974), Kaneko et al. (1997) e Barnabé et al. (2005). Sugerindo assim que esta diminuição possa ter sofrido influência direta do jejum, que foi de aproximadamente 6 horas, em decorrência da manipulação dos animais para a coleta do material analisado, bem como, o mencionado por Henry (2001), quando a glicose do líquido sinovial sofreu um equilíbrio com a glicose sanguínea.

\section{CONCLUSÕES}

Diante dos achados do presente estudo pode-se ver que os animais empregados apresentavam alterações dentárias leves e assim não foram capazes de promoverem alterações físico-químicas e citológicas no líquido sinovial dos animais dos diferentes grupos.

Foi possível observar que o tratamento dentário, destas alterações, não foi capaz de promover alterações no líquido sinovial.

As diferentes idades, determinadas entre os grupos, revelou que os animais mais velhos apresentaram uma diminuição do volume de líquido na articulação temporomandibular, promovendo ainda o aumento da densidade e proteína total no líquido sinovial.

Agradecimentos.- Fundação de Apoio à Pesquisa do Distrito Federal (FAPDF) pelo apoio financeiro e ao $1^{\circ}$ Regimento de Cavalaria de Guarda e todos que ali contribuíram gentilmente com a realização deste trabalho.

\section{REFERÊNCIAS}

Barnabé P.A., Cattelan J.W., Cadioli F.A. \& Godoy R.F. 2005. Características físico-químicas e citológicas do líquido sinovial da bainha tendínea digital de equinos. Arq. Bras. Med. Vet. Zootec. 57(3):288-294.

Boon G.D. 1997. Synovial fluid analysis: a guide for small animal practitioners. Vet. Med. 92:443-451.

Carmalt J.L., Townsend H.G., Jansen E.D. \& Cymbaluk N.E. 2004. Effect of dental floating on weight gain, body condition, feed digestibility and fecal particle size in pregnant mares. J. Am. Vet. Med. Assoc. 225(12):1889-1893.

Curtiss P.H. 1964. Changes produced in the synovial membrane and synovial fluid by disease. Journal of Bone and Joint Surgery 46(4):873-888.

Duncan J.R. \& Prasse K.W. 1986. Veterinary laboratory medicine: clinical pathology. $2^{\text {nd }}$ ed. Iowa State University Press, Ames, p.212-214.

Easley J. 2005. Corrective dental procedures, p.305-349. In: Baker G.J. \& Easley J. (Eds), Equine Dentistry. $2^{\text {nd }}$ ed. Elsevier Saunders, Philadelphia.

Fernandez F.R., Grindem C.B. \& Lipowitz A.J. 1983. Synovial fluid analysis: Preparation of smears for cytologic examination of canine synovial fluid. J. Am. Anim. Hosp. Assoc. 19:727-734.

Fonseca A.F., Zambrano R.S., Dias G.M.B., Lima E.M.M., Alves G.E.S. \& Godoy R.F. 2009. Características físicoquímicas e citológicas do líquido sinovial da articulação temporomandibular em equinos. Pesq. Vet. Bras. 29(10):829-833.

Henry J.B. 2001. Clinical Diagnosis and Management by Laboratory Methods. $20^{\text {th }}$ ed. Elsevier Saunders, Philadelphia. 1512p.

Kaneko J.J., Harvey J.W. \& Bruss M.L. 1997. Clinical Biochemistry of Domestic Animals. 5th ed. Academic Press, London, p.885-906.

Kiehl A.R. 1997. Synovial fluid analysis. Proc. $15^{\text {th }}$ ACVIM Forum. Lake Buena Vista, Florida, p.14.

MacWilliams P.S. \& Friedrichs K.R. 2003. Laboratory evaluation and interpretation of synovial fluid. Vet. Clin. North Am., Small Anim. Pract. 33:53-178.

Mahaffey E.A. 2001. Synovial fluid, p.163-170. In: Cowell R.L. \& Tyler R.D. (Eds), Diagnostic Cytology and Hematology of the Horse. $2^{\text {nd }}$ ed. Mosby, St Louis.

Moll H.D. \& May K.A. 2002. A review of conditions of the equine temporomandibular joint. Proceedings AAEP 48:240-243.

Moyer W. 1983. Clinical use of synovial fluid analysis. Proc. $28^{\text {th }}$ Annual Convention of the American Association of Equine Practitioners, Atlanta, p.129-135.

Pagliosa G.M., Alves G.E.S. Faleiros R.R. Saliba, E.O.S. Sampaio I.B.M., Gomes T.L.S. \& Fantini P. 2006. Influência das pontas excessivas de esmalte dentário na digestibilidade e nutrientes de dietas de equinos. Arq. Bras. Med. Vet. Zootec. 58(1):94-98.

Parry B.W. 1999. Synovial fluid, p.104-119. In: Cowell R.L., Tyler, R.D. \& Meinkoth J.H. (Eds), Diagnostic Cytology and Hematology of the Dog and Cat. $2^{\text {nd }}$ ed. Mosby, St Louis. 
Piermattei D.L. \& Flo G.L. 1997. Arthrology, p.170-200. In: Piermattei D., Flo G. \& DeCamp C. (Eds), Flo's Handbook of Small Animal Orthopedics and Fracture Repair. $3^{\text {rd }}$ ed. W.B. Saunders, Philadelphia.

Pimentel L.F.R.O. 2008. Análise de parâmetros oclusais para o ajuste oclusal em equinos (Equus cabalus) estabulados. Dissertação de Mestrado em Medicina Veterinária, Faculdade de Medicina Veterinária e Zootecnia, USP, São Paulo, SP. 98p.

Ralston S.L., Foster D.L., Divers T. \& Hintz H.F. 2001. Effect of dental correction on feed digestibility in horses. Equine Vet. J. 33(4):390-393.

Rosenstein D.S., Bullock M.F., Ocello P.J. \& Clayton H.M. 2001. Arthrocentesis of the temporomandibular joint in adult horses. Am. J. Vet. Res. 262:729-735.

Sawyer D.C. 1963. Synovial fluid analysis of canine joints. J. Am. Vet. Med. Assoc. 143:609-612.
Schumacher J. 2006. The equine temporomandibular joint. In: Equine Dentistry. Proc. AAEP Focus Meeting, American Association Equine Practioners, Indianapolis.

Spiers S., May S.A. \& Bennett D. 1994. Cellular sources of proteolytic enzymes in equine joints. Equine Vet. J. 26(1):43-50.

Tew W.P. \& Hotchkiss R.N. 1981. Synovial fluid analysis and equine joint disorders. J. Equine Vet. Sci. 1:163-170.

Van Pelt R.W. 1974. Interpretation of synovial fluid findings in the horse. J, Am. Vet. Med. Assoc. 165:91-95.

Van Pelt R.W. 1962. Properties of equine synovial fluid. J. Am. Vet. Med. Assoc. 141:1051-1061.

Viitanen M., Bird J., Makela O., Schramme M., Smith R., Tulamo R.M. \& May S. 2001. Synovial fluid studies in navicular disease. Res. Vet. Sci. 71(3):201-206. 